\title{
Clinical and Epidemiological Profile of Herpes Zoster; A Cross-Sectional Study from Tertiary Hospital
}

\author{
Paudel Vikash ${ }^{* 1,5}$, Pandey Buddhi Raj ${ }^{1}$, Tripathee Richa ${ }^{1}$, Tripathee Rishabh Dev $^{2}$, Sitaula \\ Shreema $^{3}$, Dhakal Prabin ${ }^{4}$, Shrestha Dwarika Prasad ${ }^{5}$ \\ ${ }^{1}$ Department of Dermatology, Venereology and Leprosy, National Medical College, Birgunj, Parsa, Nepal \\ ${ }^{2}$ Stupa Community Hospital, Bauddha, Kathmandu, Nepal \\ ${ }^{3}$ Alka Hospital, Jawalakhel, Kathmandu, Nepal \\ ${ }^{4}$ Department of Dermatology, Manmohan Memorial Medical College, Kathmandu, Nepal \\ ${ }^{5}$ Department of Dermatology and Venereology, Institute of Medicine, Kathmandu, Nepal
}

Date of Submission : March 04, 2018

Received in Revised Form : March 19, 2018

Date of Acceptance : April 09, 2018

Date of Publishing : July 30, 2018

\section{ABSTRACT}

Background: Herpes zoster is dermatomal neuropathic disease caused by reactivation of varicella zoster virus, characterized by vesicobullous eruptions. Although, being a common cause of morbidity, there are few clinicepidemiological studies and the studies regarding the knowledge and practice among the patients are nominal.

Methods: This was descriptive observational study which included 100 consecutive patients with herpes zoster who presented to Department of Dermatology and Venereology in a Teaching Hospital, Kathmandu during the period from July 2014 to June 2015.

Results: The annual incidence was $0.55 \%$. Seventy two percent were males and 28 percent were females with the $\mathrm{M}: \mathrm{F}=2.5: 1$. The average age of patients and mean duration of disease was 40.4 years and 5.5 days respectively. Ninety five percent were managed at OPD and $5 \%$ of them needed hospitalization. Most common dermatome involved was thoracic $(50 \%)$ followed by cervical $(20 \%)$. Twelve percent had one or more provocative features including diabetes, steroid use, chemotherapy, surgical trauma etc. Twenty patients had definite history chicken pox.
Twenty-five percent had local complication at the time of presentation. Fifty two percent had themselves identified the lesion as herpes zoster. However, only 10 had some knowledge about it. Twelve percent had visited traditional healers prior to hospital arrival.

Conclusions: The results show varied clinicoepidemiologic patterns of herpes zoster. Major patient have less knowledge about it. A larger study would be necessary for better clinical, epidemiological and social behavioral data. Because of ignorance and tradition, awareness program should be conducted to reduce potential complications.

Keywords: Epidemiology; Herpes Zoster; Knowledge, Nepal

*Corresponding Author: Dr Vikash Paudel, National Medical College, Birgunj-15, Nepal, luck vik@hotmail.com, vikashpoudel@iom.edu.np

\section{INTRODUCTION}

Herpes zoster (HZ), also known as Shingles, is a benign localized viral neuro-dermopathic disease caused by varicella zoster virus (VZV). ${ }^{1}$ VZV is a ubiquitous, double-stranded DNA herpes virus with a genome that contains at least 
70 gene products. ${ }^{2}$ It is clinically characterized by a grouped vesiculo-bullous eruptions confined to dermatomes. In Nepali language, it is termed as JANAI KHATIRA i.e. holy thread wound, because of the pattern of herpes zoster in thoracic region is like as the holy thread worn. (Figure 1) The current concept of the development of the lesion as postulated by HopeSimpson in 1965, that primary infection presents as chicken-pox (CP), and $\mathrm{HZ}$ is a reactivation of the latent virus established in one or more sensory root ganglia during primary clinical or subclinical infection early in life or occasionally in utero. ${ }^{3,4}$ Although, HZ being a common cause of morbidity, there are very few studies on the epidemiology, clinical profiles and the studies regarding the knowledge and awareness among the patients with HZ in South Asia. ${ }^{5}$ Here-in, we describe a hospital-based study of herpes zoster in a central hospital of Nepal

\section{MATERIALS AND METHODS}

This cross sectional observational study was conducted department of dermatology, and venereology, university teaching hospital, Kathmandu, Nepal, during the period of one year from July 2014 to June 2015. Nonprobability purposive sampling was the method of sampling. All the patients with clinical diagnosis of herpes zoster as determined by dermatologist were taken as a case. Ethical approval was taken prior the commencement of the study. Informed consent was obtained from patients or their guardians for enrollment into the study and taking clinical photographs. Total number of patients was 100 who were consecutively enrolled in the study. The general demographic profiles such as age, gender, address, religion and occupation were noted. A complete history about the prodromal features, symptoms, types and pattern of skin lesions, nature, intensity and duration of pain were noted. Similarly, previous history of chicken pox and past attack of herpes zoster were elicited. They were also inquired about history of provocative risk factors such as drugs, trauma, surgery, immunosuppressive and cytotoxic chemotherapy or radiotherapy, HIV infections, diabetes mellitus, tuberculosis, asthma or chronic obstructive pulmonary disease. All the patients were asked about knowledge about herpes zoster, their causative factor and practice of visiting traditional healers. A complete dermatological examination regarding morphology, pattern of the lesions, the segment of involvement, laterality, dissemination of the lesions etc. were noted. Similarly, any changes in the periphery were also noted. Whenever necessary, opinion from other specialists was sought. All the details were recorded in preformed proforma and analyzed statistically.

\section{RESULTS}

The annual incidence of herpes zoster was $0.55 \%$. Out of 100 cases, $72 \%$ were males and $28 \%$ were females $(\mathrm{M}: \mathrm{F}=2.5: 1)$. The mean age of the patients was 40.4 years which ranged from 2-80 years. The distribution of age and gender is given in Table 1.

Table 1: Age and gender distribution of Herpes Zoster

\begin{tabular}{|l|l|c|c|c|}
\hline \multicolumn{2}{|l|}{$\begin{array}{c}\text { Age and gender } \\
\text { distribution }\end{array}$} & \multicolumn{2}{|c|}{ Sex } & \multirow{2}{*}{ Total } \\
\cline { 2 - 5 } Age & Less than 10 & 2 & 2 & 4 \\
\cline { 2 - 5 } & $10-19$ & 6 & 6 & 12 \\
\cline { 2 - 5 } & $20-29$ & 20 & 4 & 24 \\
\cline { 2 - 5 } & $30-39$ & 12 & 2 & 14 \\
\cline { 2 - 5 } & $40-49$ & 4 & 0 & 4 \\
\hline $50-59$ & 8 & 6 & 14 \\
\hline & $60-69$ & 12 & 6 & 18 \\
\hline $70-79$ & 6 & 2 & 8 \\
\cline { 2 - 5 } & $80-89$ & 2 & 0 & 2 \\
\hline \multicolumn{2}{|c|}{ Total } & $\mathbf{7 2}$ & $\mathbf{2 8}$ & $\mathbf{1 0 0}$ \\
\hline
\end{tabular}

The maximum incidence was in the age group of 20-29 years (24\%), which is followed 60-69 years (18\%). Minimum incidence was observed in the age group of $80-89$ years and $1-10$ years which were $2 \%$ and $4 \%$ respectively. Mean duration of disease was 5.5 days with range of 1-25 days and mean prodromal duration was 2.8 days with range of 1-10 days. Prodromal symptoms were present in half of the patients which were burning sensation (28\%), followed by pain $(10 \%)$, redness $(10 \%)$ and hyperesthesia $(2 \%)$. The common presenting symptoms were vesiculations (90\%), pain (88\%), myalgia (24\%), watering from eyes $(16 \%)$ and headache $(12 \%)$.

The dermatomal distribution of zoster is given in Table 2. Thoracic dermatome was commonly 
affected (50\%) and among thoracic segment was the commonest. It was follow by the cervical nerve (20) and trigemina [ophthalmic branch (16), maxillary (2)]. (Fi 1,2 and 3) Two patients had dissemina lesions with involvement of more than dermatome. Majority of the patient had 1 sided lesion (58) and forty two cases on the side.

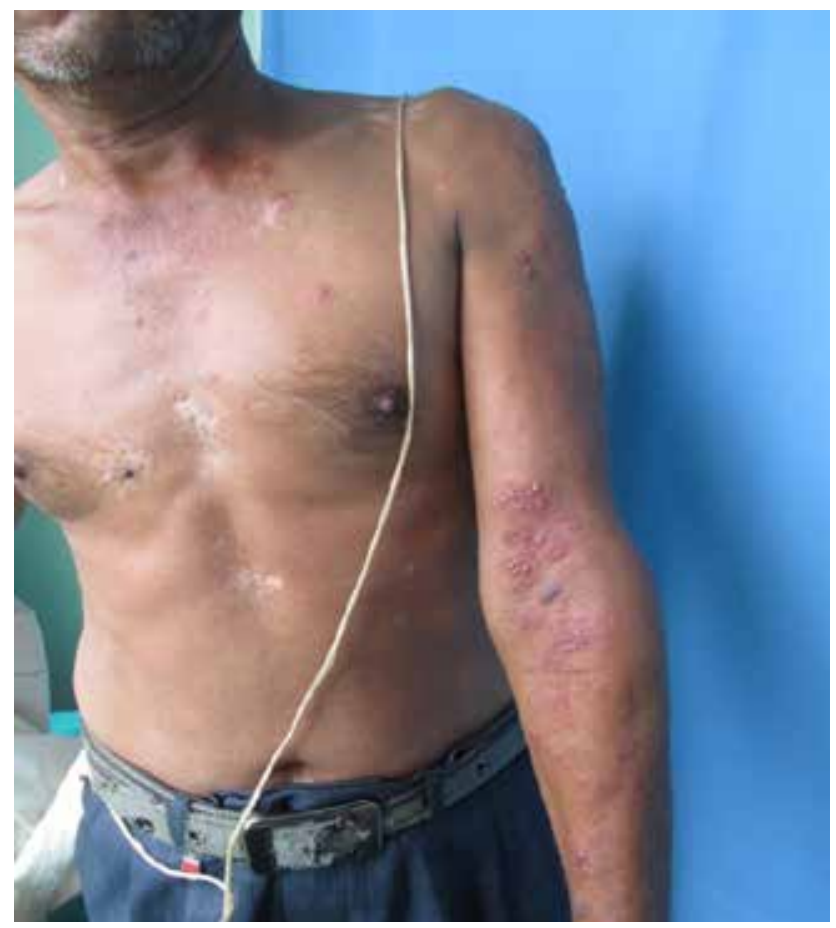

Figure 1: Herpes Zoster

\section{(janai khatira, holy thread rash)}

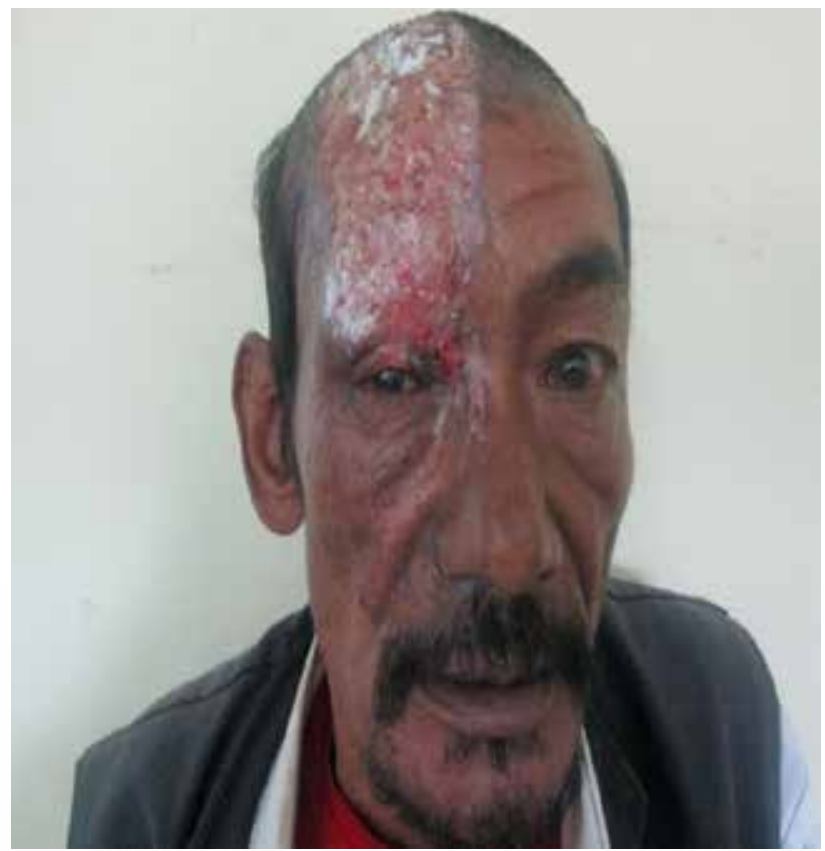

Figure 2: Herpes zoster ophthalmicus
Table 2: Dermatome involvement according to gender in herpes zoster

\begin{tabular}{|l|l|c|c|c|}
\hline \multirow{2}{*}{$\begin{array}{l}\text { Dermatomes and gender } \\
\text { distribution }\end{array}$} & \multicolumn{2}{|c|}{ Gender } & \multirow{2}{*}{ Total } \\
\cline { 2 - 5 } & Male & Female & \\
\hline \multirow{4}{*}{ Dermatomes } & Ophthalmic & 12 & 4 & 16 \\
\cline { 2 - 5 } & Maxillary & 0 & 2 & 2 \\
\cline { 2 - 5 } & Cervical & 16 & 4 & 20 \\
\cline { 2 - 5 } & Thoracic & 38 & 12 & 50 \\
\cline { 2 - 5 } & Lumbar & 4 & 6 & 10 \\
\cline { 2 - 5 } & Sacral & 2 & 0 & 2 \\
\hline \multicolumn{2}{|l|}{ Total } & $\mathbf{7 2}$ & $\mathbf{2 8}$ & $\mathbf{1 0 0}$ \\
\hline
\end{tabular}

Being the benign nature and course of disease, 95 $\%$ were managed on out-patient basis, whereas five were hospitalized. Among hospitalized ones, majority was elderly patient (4), two had disseminated herpes zoster and three had ophthalmic zoster. The disseminated zoster was present in patient under immuno-suppressive drug for connective tissue disease. (Figure 3) Seventy percent patients had zoster associated pain (ZAP), which was moderate to severe in intensity.

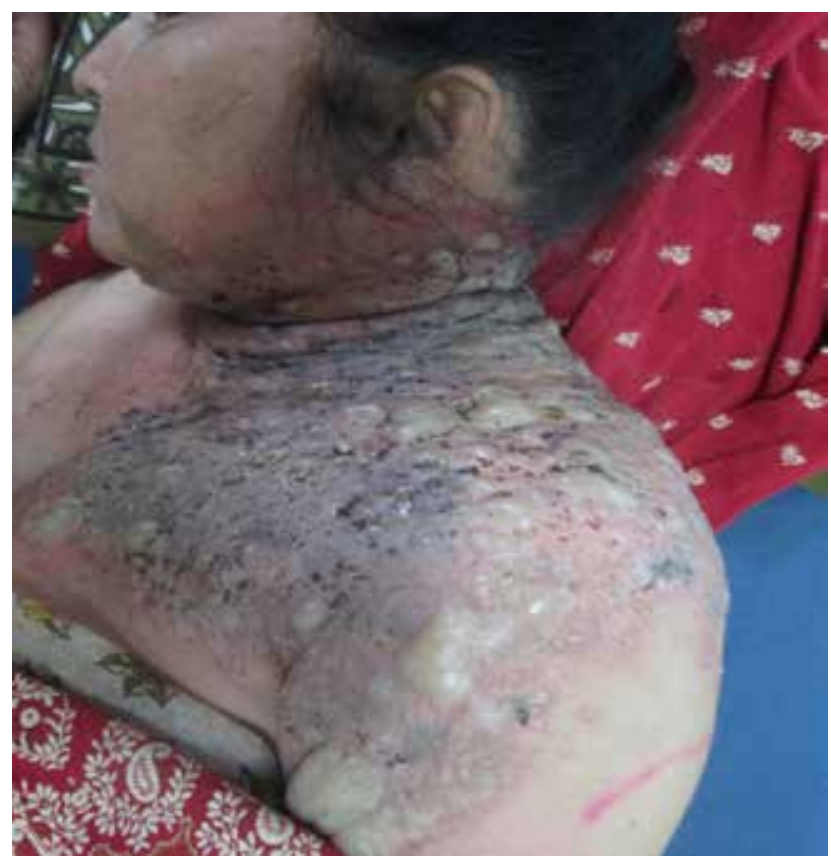

Figure 3 : Disseminated Herpes Zoster, immunosuppressed patient

Local complication was seen in one quarter of the patients which were necrosis or ulceration of skin $(10 \%)$, irritant contact dermatitis (5\%), keratitis (5\%), super-added bacterial infection (4\%), and keloid formation (1\%). Post herpetic neuralgia was seen in $15 \%$ of patients. The systemic complications were not seen in any patients. Out of 100 cases, only 10 had definite history of chicken pox and none had past history of herpes 
zoster. Only, twelve patients had one or more suspected provoking factors. Among them, six were diabetic, four were on steroids, one patient had cancer with chemotherapy and one had done hysterectomy just prior to $\mathrm{HZ}$.

Fifty two patients themselves had identified the lesion as HZ. Among them; only 10 had some short of knowledge about it. Twelve of the patients had visited traditional healer prior to presentation whereas in eight of them, the traditional healer had applied herbal medicines and painted some animals in the periphery of lesion with the belief of resolution. (Figure 4)

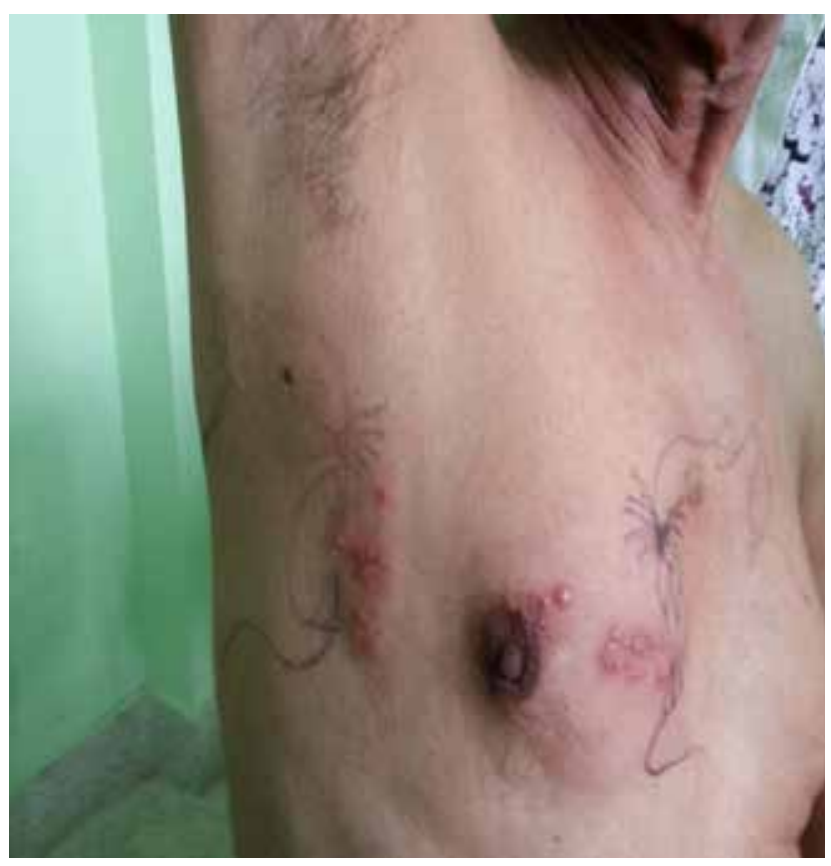

Figure 4 : Herpes zoster, thoracic dermatome (painting of animal in periphery)

\section{DISCUSSION}

Herpes zoster is recognized since ancient times and described in early medical literature. ${ }^{6}$ But, we lack epidemiological and clinical data because of self-resolution of disease and limited studies, in our part of the world.

The present study was conducted to find the epidemiological, clinical and social parameters of HZ. The incidence of $\mathrm{HZ}$ was $0.55 \%$ which was less than the previous study in Nepal, ${ }^{7}$ The incidence rate of $\mathrm{HZ}$ ranged between 3 and 5/1000 person-years in North America, Europe and Asia-Pacific. ${ }^{8}$ There was slightly male preponderance with $\mathrm{M}: \mathrm{F}=2.6: 1$ which his similar with the studies from Nepal ${ }^{7}$, India ${ }^{9}$ and Sri Lanka. ${ }^{10}$ The finding is contrast to global estimates where female preponderance is more common. ${ }^{11}$ This could be probably due to male predominance of society, frequent visit to hospital.

$\mathrm{HZ}$ is described as commonly occurring in the elderly and the immuno-compromised patients and the incidence is said to increase with age. ${ }^{12}$ This study, however showed majority of cases in the age group of 21-30 years with a mean age of 40 years. The results are similar with that from Nepal ${ }^{7}$, India ${ }^{9}$ and Srilanka. ${ }^{10}$

Hope-Simpson and Ragozzino et al believed that HZ is classically associated with physical stress. ${ }^{3,13}$ In ours, except for twelve individuals, others were in state of good health. The common provocative factors were diabetes mellitus $(6 \%)$, systemic steroids (4\%), chemotherapy (1\%) and post-operative stress $(1 \%)$. The risk factors or the provocative factors were similar to the other studies whereas none of our patient had HIV unlike other studies. ${ }^{12}$

The presenting symptoms vesiculations, pain, muscle pain, watering from eyes, headache were common as revealed in metaanalysis. ${ }^{12}$ The presence of zoster associated pain (ZAP) has been reported in $95 \%$ and $94.6 \%$ of cases. ${ }^{12,14}$ The most common dermatome was thoracic $(50 \%)$ followed by cervical $(20 \%)$, cranial $(18 \%)$ and lumbosacral. (Table 2) This is which is similar to various prospective and retrospective studies. $9,14,15$

The common complications were irritant contact dermatitis, ulceration, secondary infections, keratitis, post herpetic neuralgia, keloid formation etc. The post herpetic neuralgia was present in $15 \%$ of patient and more common in elderly. ${ }^{8,16}$ More than half (52\%) of the patient had diagnosed the rash as that of herpes zoster but a few $(10 \%)$ patients had knowledge about herpes zoster. This was similar to a survey conducted which showed higher knowledge in developed countries and poor knowledge in developing ones. ${ }^{5}$ Twelve percent of the patients were initially handled by traditional 
healers, with a belief on them, who used to apply herbal medicines and draw animal figure in the periphery of lesions. Some of the visitors believed that the circumferential involvement of herpes zoster is fatal. Visiting the traditional healer for herpes zoster is also common in some places. ${ }^{17,18}$ This is believed to delay in diagnosis \& timely treatment, ultimately contributing in various complications. ${ }^{19}$

The limitation of the study was lesser number of participants. Being a hospital based study, the study did not give the true incidence of the herpes zoster in the community. There was difficulty in obtaining the knowledge among the participants about the herpes zoster because of the medical terminologies involved.

\section{CONCLUSION}

The results and patterns were almost similar with the Asian studies and different from Western and European ones. This could probably be due to the younger population or a true incidence in Asians. Though being common nature of problem and its associated considerable economic burden and health morbidity, clinicepidemiological data are lacking. Because of the poor knowledge about the $\mathrm{HZ}$ and traditional faith among patients, awareness program should be conducted regarding the seriousness of the disease and potential complication associated with it. A larger and broader study would be necessary formore accurate results on clinical, epidemiological and social behaviors of $\mathrm{HZ}$.

\section{ACKNOWLEDGEMENT}

We are thankful to all the patients who participated in the study, faculties and staffs of department of dermatology-TUTH and Dr. Deepa Chudal for her constant secretarial support.

\section{REFERENCES}

1. Oxman MN, Schmader KE. Varicella and herpes zoster. In: Goldsmith LA, Katz SI, Gilchrest BA, Paller AS, Leffell DJ, Wolff K, editors. Fitzpatrick's dermatology in general medicine. 8th ed. New York: McGraw-Hill; 2012;2383-2401
2. Cohen JI. The varicella-zoster virus genome. Curr Top Microbiol Immunol. 2010;342:1-14.

3. Hope-Simpson RE. The Nature of Herpes Zoster: A Long-Term Study and a New Hypothesis. Proc R Soc Med. 1965; 58:920.

4. Oxman MN. Herpes Zoster Pathogenesis and Cell-Mediated Immunity and Immunosenescence. J Am Osteopath Assoc. 2009; 109(6_suppl_2):S13-S17.

5. Paek E, Johnson R. Public awareness and knowledge of herpes zoster: results of a global survey. Gerontology. 2010; 56(1):2031.

6. Muehlenbachs A. Viruses and Man: A History of Interactions. Clin Infect Dis. 2015 Jun 15;60(12):1877-8.

7. Kayastha B, Shrestha P, Shrestha R, Lama L. Changing Profile of Herpes Zoster in Nepal: A Hospital-Based Study. Nepal Journal of Dermatology, Venereology \& Leprology. 2009; 8(1):1-4.

8. Kawai K, Gebremeskel BG, Acosta CJ. Systematic review of incidence and complications of herpes zoster: towards a global perspective. BMJ Open. 2014; 4(6).

9. Aggarwal SK, Radhakrishnan S. A clinicoepidemiological study of herpes zoster. Armed Forces Med J India. 2016;72(2):175177.

10. Katugampola S, Katugampola G. A clinicoepidemiological study of herpes zoster. The Ceylon Journal of Medical Science. 1999;36 (1), 1-7.

11. Yawn BP, Gilden D. The global epidemiology of herpes zoster. Neurology. 2013;81(10):928-930.

12. Kawai K, Yawn BP. Risk factors for herpes zoster: a systematic review and meta-analysis. Mayo Clin Proc. 2017;92:1806-1821.

13. Ragozzino M, Melton L, Kurland L, Chu C, Perry H. Population-based study of herpes zoster and its sequelae. Medicine. 1982; 61(5):310-316.

14. Goh CL, Khoo L. A retrospective study of the clinical presentation and outcome of herpes zoster in a tertiary dermatology outpatient referral clinic. Int J Dermatol. 1997;36(9):667-672. 
15. Abdul Latheef EN, Pavithran K. Herpes zoster: a clinical study in 205 patients. Indian J Dermatol. 2011;56(5):529-532.

16. Hillebrand K, Bricout H, Schulze-Rath R, Schink T, Garbe E. Incidence of herpes zoster and its complications in Germany, 2005-2009. J Infect. 2015;770(2):178-186.

17. Birhan W, Giday M, Teklehaymanot T. The contribution of traditional healers' clinics to public health care system in Addis Ababa, Ethiopia: a cross-sectional study. J Ethnobiol Ethnomed. 2011;7(1):39.

18. McMillen $H$. The adapting healer: pioneering through shifting epidemiological and sociocultural landscapes. Soc Sci Med. 2004;59(5):889-902.

19. Komolafe O, Ogunleye O, Fasina O, Komolafe O. African traditional medication and keloid formation in herpes zoster ophthalmicus. Nigerian journal of clinical practice. 2011 ; 14(4):479-481. 